\title{
INHIBITORY EFFECT OF STATIN PRODUCED BY ENDOPHYTE FUSARIUM SPECIES ISOLATED FROM AZADIRACHTA INDICA
}

\author{
A. A. Fulzele*, Asifa Qureshi** and V A. Fulzele*** \\ *Shri Mathuradas Mohota College of Science, Umrer Road, Nagpur, Maharashtra, India \\ **EGU, National Environmental Engineering Research Institute (CSIR), Nagpur \\ *** Shri Shivaji Science College, Congress Nagar, Nagpur. \\ Corresponding Author: ashwatf@gmail.com
}

\begin{abstract}
:
Endophytes are organisms associated with plant tissues that are less explored ecological niche of novel fungi and bacteria. Such organisms are rich sources capable of producing bioactive metabolites, having immense pharmaceutical significance. Azadirachta indica is an evergreen tree with ethno-medicinal properties. In this investigation, an attempt has been made to isolate endophytes from different tissues of A.indica such as stem, leaf and bark. An endophyte identified as Fusarium decemcellulare isolated from leaf tissues, this endophytic fungus showed capacity of lovastatin production when subjected to solid state fermentation. The inhibitory effect of lovastatin extract from this endophytic Fusarium sp. on the growth of Sacchromyces cerevisiae was studied.
\end{abstract}

Key words: - Azadirachta indica, Fusarium, lovastatin, inhibitory, secondary metabolites.

\section{INTRODUCTION:}

\section{Statins:}

Statins are the group of compounds which are produced by fungi as secondary metabolites by Polyketide pathway. The basic structure of natural statins consists of hexahydronapthalene part and a polyketide part. Though statins are naturally produced compounds by certain microorganisms, it can be produced synthetically or semi synthetically (Huse et al 1998). Statins are significant for their bioactivities and pharmaceutical value. It has been highlighted that among top best selling drugs in 1995, six out of them are from fungal origin (Bhilabutra et al 2007). Statins are capable of producing benefits like inhibitory action on different pathogenic fungi (Macreadie2000).

Few investigations reports the ability of statins to reduce mortality due to cardiac disease and to some extent reduce cancer incidences on their combined application and differences Blais et al (2000).Statins have been also studied for their combined application and different antimycotics.

Endophytes that reside in the plant are found to be rich source of secondary metabolites, Kumar (2015). Present investigation is an attempt to study inhibitory activity of one such metabolite lovastatin from endophyte of Azadirachta indica.

\section{MATERIAL \& METHODS:}

For isolation of endophytic fungus from Neem tree, leaves were surface sterilized and placed aseptically on sterilized potato dextrose agar plates and incubated for five days at $25^{\circ} \mathrm{C}$.

For lovastatin production, solid state fermentation was carried out by using wheat bran as substrate with $70 \%$ moisture content and inoculating spore suspension of isolated fungi. The experimental set in triplicate along with control was incubated for 10 days at $25^{\circ} \mathrm{C}$.

After completion of fermentation, lovastatin was extracted by ethyl acetate extraction 
method (Raghunath 2012) and confirmed with HPLC analysis.

Lovastatin inhibitory activity

To study Inhibitory effect of lovastatin on growth of Sacchromyces cerevisiae, $3 \mathrm{ml}$ of yeast extract peptone dextrose (YEPD) liquid medium inoculated with $100 \mu \mathrm{l}$ of 16 old yeast suspensions. This culture was incubated at $250 \mathrm{rpm}$ for 25 hours samples withdrawn periodically after intervals of 5 hours and analyzed for growth by recording O D at 540 $\mathrm{nm}$.

Lovastatin inhibitory effect was evaluated by adding different lovastatin standard concentration $(0.5,1.0,1.5$ and $2.0 \mathrm{mg} / \mathrm{ml})$ to culture media and lovastatin deprived biotic controls in parallel were also grown (positive control) (Cabral 2010).

The lovastatin inhibitory effect was studied on the growth of the test organism Sacchromyces cerevisiae. To perform this experiment lovastatin standard in increasing concentration was prepared $(0.5,1.0,1.5,2.0$ $\mathrm{mg} / \mathrm{ml}$ ) in triplicates. YEPD liquid medium was used to maintain growth conditions of Sacchromyces cerevisiae. The test organism 16 hours old suspension was inoculated in each standard tube along with positive control in aliquots of $100 \mu 1$ and after every 5 hours of intervals periodic densitometry analysis was done at $550 \mathrm{~nm}$.

For studying lovastatin inhibitory effect, experimental tubes containing $100 \mu \mathrm{l}$ and $200 \mu 1$ of fungal extracts of Fusarium decemcellulare was added to experimental tube containing YEPD medium inoculated with 100 $\mu \mathrm{l}$ of $16 \mathrm{hrs}$ old Sacchromyces cerevisiae.Densitometric analysis was done after interval of 5 hours up to $25 \mathrm{hrs}$. The experiment was done in triplicates. From the readings graphs were constructed for every $5 \mathrm{hrs}$.

\section{RESULT \& DISCUSSION:}

In this study inhibitory effect of statin (lovastatin) produced from endophyte of Azadirachta indica was studied on the growth of yeast. Azadirachta indica a highly medicinal plant was source for isolation of endophytes. In this study Fusarium decemcellulare as isolated from the leaves of Neem tree. This fungus was identified on the basis of colony and morphological characteristics. On potato dextrose Agar plates this fungus show dark red pigmentation with colonies appearing dark red to wine in color. Microscopic examination shows vegetative mycelium with conidia formation (Plate No.1).

\section{Inhibitory effect of Lovastatin:}

After completion of solid state fermentation, lovastatin produced by fungus was extracted by ethyl acetate extraction method (Kumar 2000Raghunath 2012,) and analyzed by HPLC to detect the presence of lovastatin from the peak of HPLC chromatogram.

\section{Inhibitory effect of standard lovastatin on the growth of Sacchromyces cerevisiae:}

During the study that carried out for 25 hours at intervals of 5 hours each, at $5 \mathrm{mg} / \mathrm{ml}$ maximum lovastatin inhibition was found after $5 \mathrm{hrs}$.when $1 \mathrm{mg} / \mathrm{ml}$ of concentration was taken maximum inhibition was found at $25 \mathrm{hrs}$ of incubation at $540 \mathrm{~nm}$ wavelength whereas for $1.5 \mathrm{mg} / \mathrm{ml}$ and $2.0 \mathrm{mg} / \mathrm{ml}$ of standard concentration, lovastatin maximum inhibitory effect on the growth of Sacchromyces cerevisiae was obtained at 20 hours of incubation (Table no. 1 and Figure no.1).

Table No.1 shows inhibitory effect of standard lovastatin on growth of Sacchromyces cerevisiae on different wavelengths that were studied to standardize suitable wavelength to study inhibitory effect of lovastatin.

However when inhibitory effect of lovastatin containing Fusarium decemcellulare fungal 
extract $(100 \mu \mathrm{l})$ was studied, the maximum inhibition as observed as 0.59 at $540 \mathrm{~nm}$ wavelength at 20 hours of incubation on the growth of Sacchromyces cerevisiae and that of $200 \mu \mathrm{l}$ of lovastatin extract showed inhibition at 15 hours of interval as 0.92 at $540 \mathrm{~nm}$ wavelength. When compared with positive control deprived of lovastatin, Sacchromyces cerevisiae, which indicated the inhibitory effect of lovastatin extract of Fusarium decemcellulare at concentration of $100 \mu \mathrm{l}$ and $200 \mu \mathrm{l}$ is due to lovastatin in the extract (Table No. 2 and Figure No.2).Table no.2 shows inhibitory effect of lovastatin effect of endophytic Fusarium decemcellulare at different wavelength to identify correct wavelength of absorbance.

The results obtained from optical densitometry measurements indicated that the lovastatin inhibitory effect towards the $15^{\text {th }}$ hour interval that is depicted in graph. The lovastatin from inhibits the growth of Sacchromyces cerevisiae by inhibiting growth due to its increasing concentration. Yeast growth measurement was progressively inhibited as lovastatin concentration was increased. The highest lovastatin concentration that led to strongest growth abolishment was found to be after around 15 hours of cultivation (Plate No.2).

\section{CONCLUSION:}

The study concludes that fungal endophyte of Azadirachta indica produces secondary metabolites. Fusarium decemcellulare the isolated endophyte has ability to produce lovastatin. Lovastatin production capacity was determined by HPLC analysis. The inhibitory activity of lovastatin on Sacchromyces cerevisiae depicts its antifungal potential.

\section{REFERENCES:}

Bhilabutra,W.,T.Techowisan,J.F.Peberdy and S.Lumyong,2007,Antimicrobial activity of bioactive compounds from Periconia siamensis

CMUGE015.Res,J.Microbiol.,2:749-755

Blais L, Desgagné A, LeLorier J (2000) 3hydroxy-3 methylglutaryl coenzyme A reductase inhibitors and the risk of cancer: a nested case control study. Arch Intern Med,

160:2363-

2368doi:10.1001/archinte.160.15.2363

Cabral ME, Delgado OD, Sampietro DA, Catalan CA, Figueroa LIC, Farina JI . Antifungal Activity and the potential Correlation with Statin-Producing ability: An Optimized screening applied to Filamentous Fungi from Las Yungas Subtropical Rainforest. Research Journal of Microbiology 2010; 5 9:833-848

Huse D.M.,M.W.Russell,J.D.

Miller,D.F.Kraemer,R.B.

D'

Agostino,R.C.Ellison and S.C. Hartz, (1998a). Cost effectiveness of statins.Am.J.Cardiol.,82:1357-1363.

Kharwar RN,Verma VC, Gond SK, Harper JK, Hess WM, Ma C, Ren Y, Strobel GA Javanicin an antibacterial Naphthaquinone from endophytic fungus of Neem, Chloridium sp." Current Microbiology 2009; 58:233238.

Kumar A G, Robert Antony A, V. Rajesh Kannan (2015). Exploration of endophytic microorganisms from selected medicinal plants and their control potential to multi drug resistant pathogens Journal of Medicinal Plants Studies; 3(2): 49-57

Kumar MS, Jana SK, Senthil V, Shashanka S, Kumar SV, Sadhukhan AK. (2000) Repeated fed batch process for improving lovastatin production. Process Biochem.; 36:363-8.

Macreadie IG, Johnson G, Schlosser T, Macreadie PI (2006) Growth inhibition of Candida species and Aspergillus fumigatus 
by statins. FEMS Microbiol Lett 262:9-13.

Moen MD, Lyseng-Williamson

Raghunath R, Radhakrishna A, Angayarkarnni isolated fromTaxus baccata.Int.J .of Appl.Biol And pharm.Tech 2012; 3(3):342351.
J,Palaniswamy
M. Production
and
cytotoxicity studies of lovastatin from
Aspergillus niger an endophytic fungi

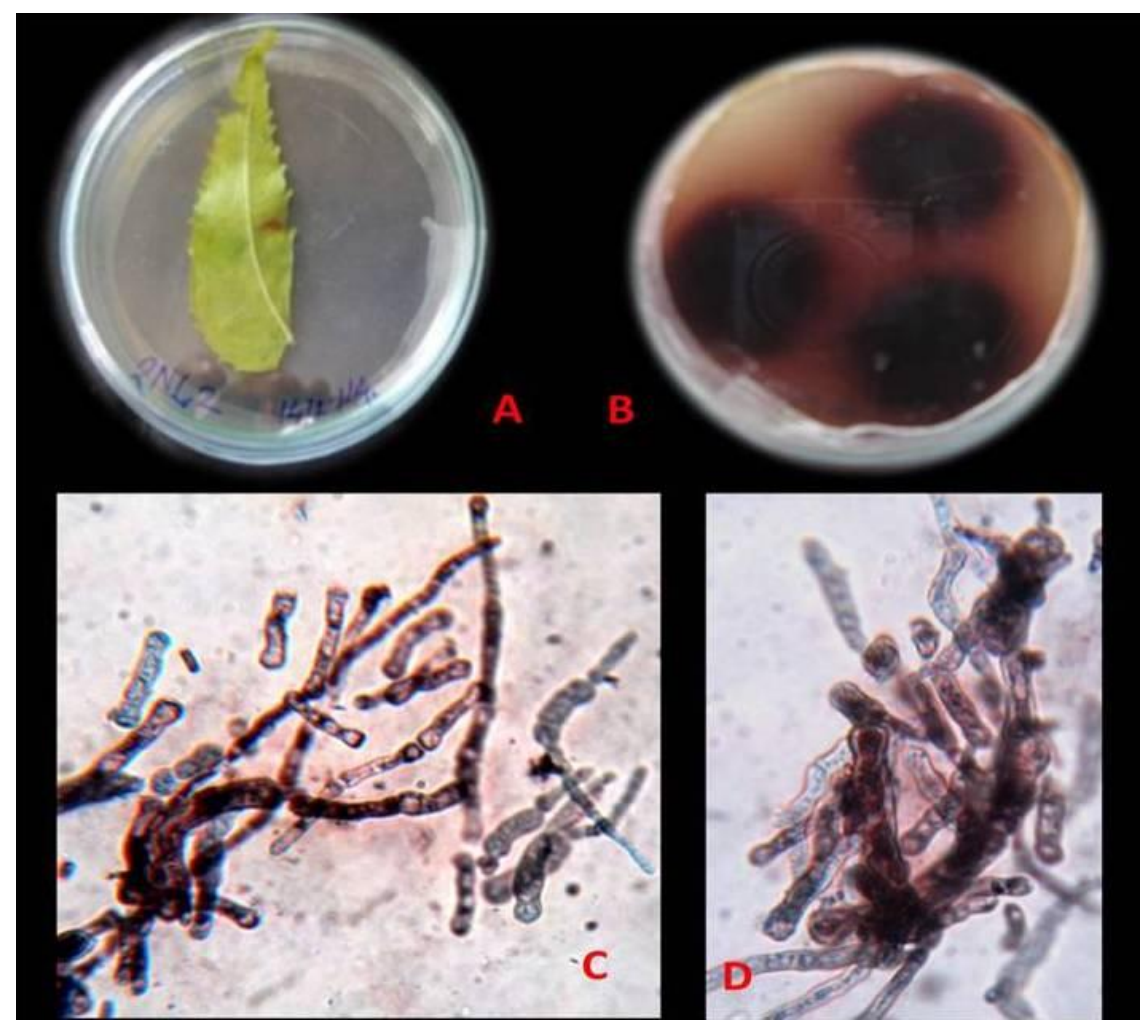

Plate No.1: a. Isolation of endophytes from leaves of Azadirachta indica. B. colony characterization c. and d. Fusarium decemcellulare.

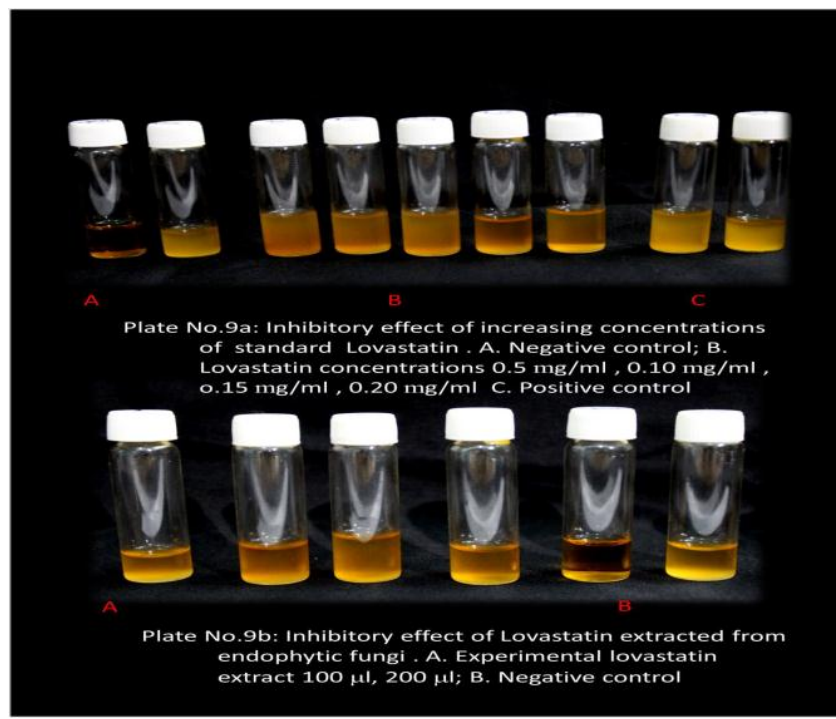

Plate No. 2: Inhibitory effect of lovastatin extracted from

Fusarium decemcellulare on Sacchromyces cerevisiae 


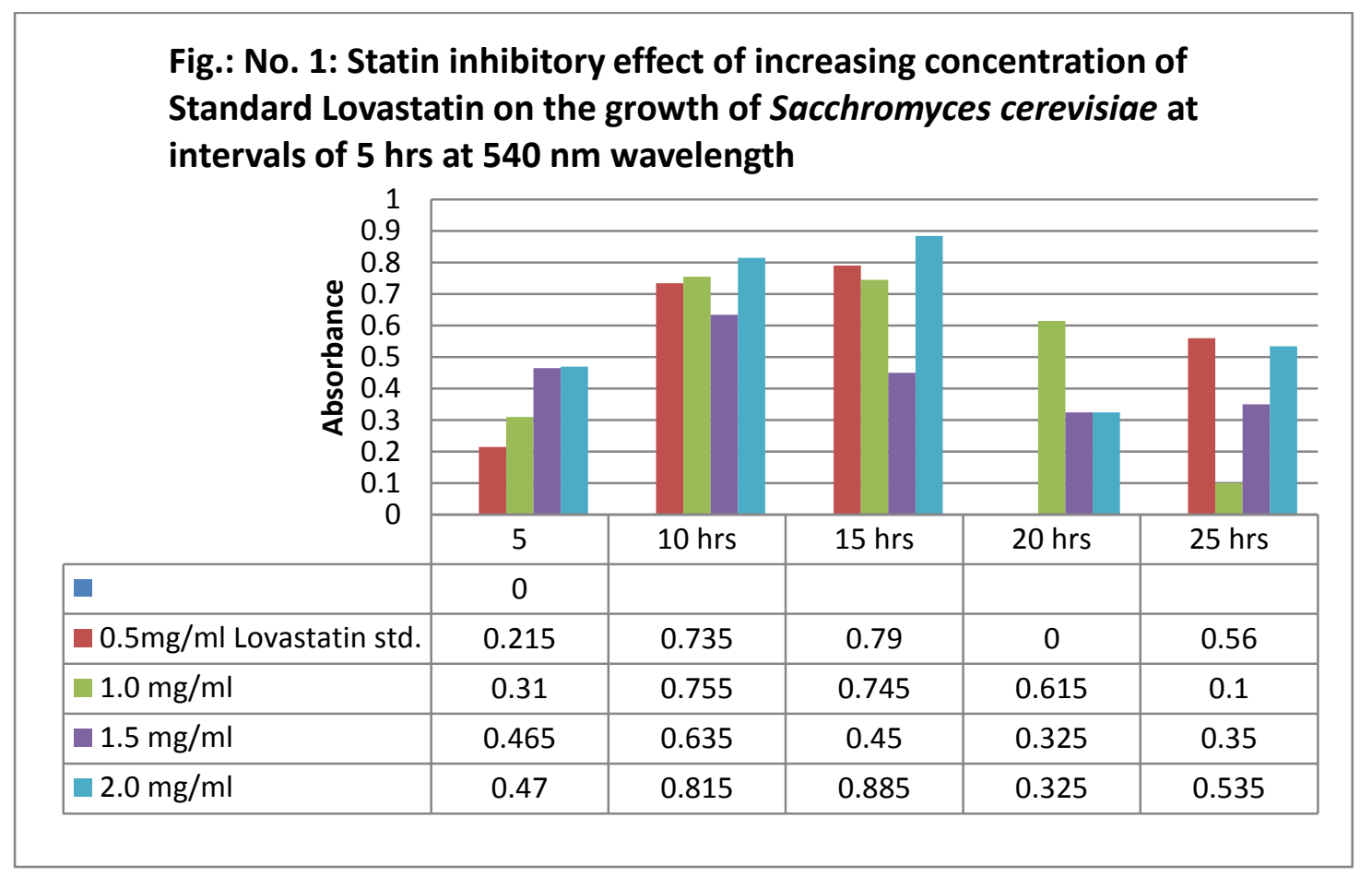

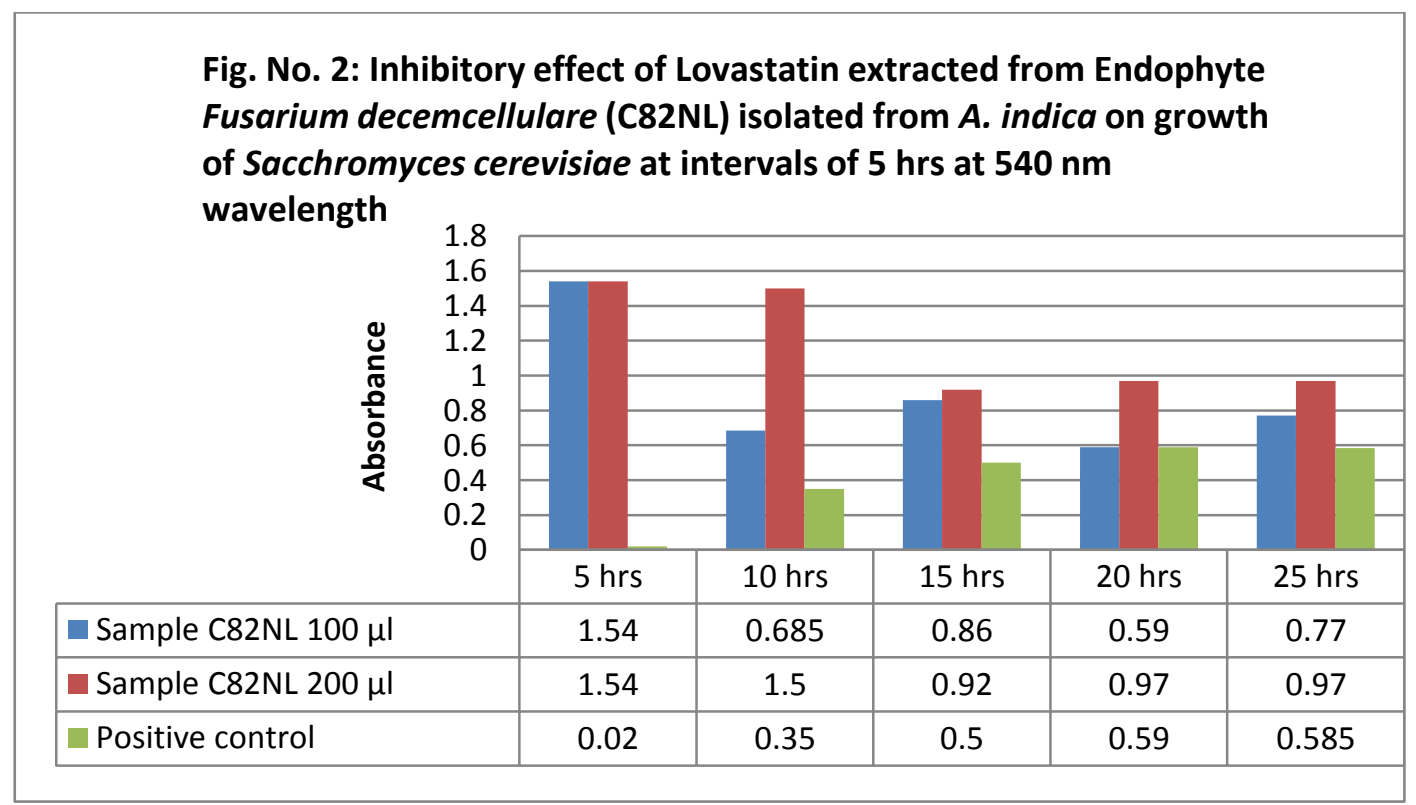




\begin{tabular}{|c|c|c|c|c|c|c|}
\hline Lovastatin standard & Wavelength (nm) & $5 \mathrm{hr}$ & $10 \mathrm{hrs}$ & $15 \mathrm{hrs}$ & $20 \mathrm{hrs}$ & $25 \mathrm{hrs}$ \\
\hline \multirow{4}{*}{$0.5 \mathrm{mg} / \mathrm{ml}$} & 510 & 0.55 & 1.045 & 1.16 & 1.05 & 0.83 \\
\hline & 520 & 0.565 & 0.89 & 1.17 & 1.05 & 0.85 \\
\hline & 540 & 0.215 & 0.735 & 0.79 & 0.665 & 0.56 \\
\hline & 570 & 0.43 & 0.835 & 0.99 & 0.88 & 0.73 \\
\hline \multirow{4}{*}{$1.0 \mathrm{mg} / \mathrm{ml}$} & 510 & 0.625 & 1.05 & 1.09 & 0.95 & 0.35 \\
\hline & 520 & 0.67 & 1.1 & 1.11 & 0.99 & 0.38 \\
\hline & 540 & 0.31 & 0.755 & 0.745 & 0.615 & 0.1 \\
\hline & 570 & 0.495 & 0.925 & 0.945 & 0.8 & 0.27 \\
\hline \multirow{4}{*}{$1.5 \mathrm{mg} / \mathrm{ml}$} & 510 & 0.785 & 0.95 & 0.79 & 0.61 & 0.605 \\
\hline & 520 & 0.83 & 0.985 & 0.85 & 0.625 & 0.64 \\
\hline & 540 & 0.465 & 0.635 & 0.45 & 0.325 & 0.35 \\
\hline & 570 & 0.665 & 0.83 & 0.65 & 0.475 & 0.52 \\
\hline \multirow{4}{*}{$2.0 \mathrm{mg} / \mathrm{ml}$} & 510 & 0.78 & 1.135 & 1.23 & 0.605 & 0.795 \\
\hline & 520 & 0.81 & 1.18 & 1.295 & 0.62 & 0.83 \\
\hline & 540 & 0.47 & 0.815 & 0.885 & 0.325 & 0.535 \\
\hline & 570 & 0.73 & 1 & 1.085 & 0.485 & 0.7 \\
\hline
\end{tabular}

\begin{tabular}{|c|c|c|c|c|c|c|}
\hline Sample name & Different & Incub & erval & & & \\
\hline & Wavelength (nm) & $5 \mathrm{hrs}$ & $10 \mathrm{hrs}$ & $15 \mathrm{hrs}$ & $20 \mathrm{hrs}$ & $25 \mathrm{hrs}$ \\
\hline Sample C82NL & 510 & 1.93 & 1.045 & 1.15 & 0.885 & 0.88 \\
\hline extract $100 \mu 1$ & 520 & 1.87 & 1.05 & 0.99 & 0.88 & 0.75 \\
\hline & 540 & 1.54 & 0.685 & 0.86 & 0.59 & 0.77 \\
\hline & 570 & 1.69 & 0.85 & 0.88 & 0.73 & 0.69 \\
\hline & 510 & 1.93 & 1.89 & 1.32 & 1.28 & 1.27 \\
\hline Sample C82NL & 520 & 1.87 & 1.88 & 1.3 & 1.27 & 1.3 \\
\hline extract $200 \mu 1$ & 540 & 1.54 & 1.5 & 0.92 & 0.97 & 0.97 \\
\hline & 570 & 1.69 & 1.67 & 1.09 & 1.09 & 1.1 \\
\hline & 510 & 0.35 & 0.71 & 0.83 & 0.885 & 0.85 \\
\hline & 520 & 0.34 & 0.72 & 0.89 & 0.88 & 0.915 \\
\hline Fositive control & 540 & 0.02 & 0.35 & 0.5 & 0.59 & 0.585 \\
\hline & 570 & 0.23 & 0.45 & 0.7 & 0.73 & 0.745 \\
\hline
\end{tabular}

